\title{
Changes Over Time in the Oregon Physician Orders for Life-Sustaining Treatment Registry: A Study of Two Decedent Cohorts
}

\author{
Dana M. Zive, MPH, ${ }^{1}$ Valerie M. Jimenez, BS, ${ }^{2}$ Erik K. Fromme, MD, MCR, ${ }^{3}$ and Susan W. Tolle, MD ${ }^{4}$
}

\begin{abstract}
Background: The Physician Orders for Life-Sustaining Treatment (POLST) began in Oregon in 1993 and has since spread nationally and internationally.

Objectives: Describe and compare demographics and POLST orders in two decedent cohorts: deaths in 20102011 (Cohort 1) and in 2015-2016 (Cohort 2).

Design: Descriptive retrospective study.

Setting/Subjects: Oregon decedents with an active form in the Oregon POLST Registry.

Measurements: Oregon death records were matched with POLST orders. Descriptive analysis and logistic regression models assess differences between the cohorts.

Results: The proportion of Oregon decedents with a registered POLST increased by $46.6 \%$ from 30.9\% (17,902/ $58,000)$ in Cohort 1 to $45.3 \%(29,694 / 65,458)$ in Cohort 2 . The largest increase $(83.3 \%)$ was seen in decedents 95 years or older with a corresponding $78.7 \%$ increase in those with Alzheimer's disease and dementia, while the interval between POLST form completion and death in these decedents increased from a median of 9-52 weeks. Although orders for do not resuscitate and other orders to limit treatment remained the most prevalent in both cohorts, logistic regression models confirm a nearly twofold increase in odds for cardiopulmonary resuscitation and full treatment orders in Cohort 2 when controlling for age, sex, race, education, and cause of death.

Conclusion: Compared with Cohort 1, Cohort 2 reflected several trends: a $46.6 \%$ increase in POLST Registry utilization most marked in the oldest old, substantial increases in time from POLST completion to death, and disproportionate increases in orders for more aggressive life-sustaining treatment. Based on these findings, we recommend testing new criteria for POLST completion in frail elders.
\end{abstract}

Keywords: advance care planning; frailty; POLST; resuscitation orders; serious illness

\section{Introduction}

I $\mathrm{N}$ AN ERA of increased awareness, training, and implementation of advance care planning (ACP), a populationbased approach that offers every patient the opportunity to participate is both valuable and within reach. ${ }^{1}$ The challenges and complexities inherent in any such approach create both benefit and risk, and so, it is imperative to have data systems that support safety and improvement. The Physician Orders for LifeSustaining Treatment (POLST) began in Oregon in 1993 and has since spread widely nationally and internationally. ${ }^{2-5}$ POLST-like forms allow patient preferences to be translated into actionable life-sustaining treatment orders that are portable across settings of care. -19 $^{3-9}$

To ensure that POLST forms were accessible in an emergency, in December 2009, an Oregon statute required that

\footnotetext{
${ }^{1}$ Center for Policy and Research in Emergency Medicine, Oregon Health \& Science University, Portland, Oregon.

${ }^{2}$ Center for Ethics in Health Care, Oregon Health \& Science University, Portland, Oregon.

${ }^{3}$ Department of Psychosocial Oncology and Palliative Care, Dana-Farber Cancer Institute, Boston, Massachusetts.

${ }^{4}$ Division of General Internal Medicine and Geriatrics, Center for Ethics in Health Care, Oregon Health \& Science University, Portland, Oregon.
}

(C) Dana M. Zive et al., 2018; Published by Mary Ann Liebert, Inc. This Open Access article is distributed under the terms of the Creative Commons License (http://creativecommons.org/licenses/by/4.0), which permits unrestricted use, distribution, and reproduction in any medium, provided the original work is properly credited. 
health professionals submit completed POLST forms to a statewide electronic registry (the Oregon POLST Registry) unless a patient chose to opt out. ${ }^{20}$ Since then, the Registry has received over 350,000 forms for over 220,000 patients and submissions to the Registry have steadily increased from 39,875 in 2010 to 56,950 in $2016 .{ }^{21}$ We have previously reported data from the first years of Registry operations characterizing its demographics, life-sustaining treatment order prevalence, and timing of submission in relation to death. It was understood at the time that these data would likely change over time as the Registry became more established and "mature." 15 Therefore, with the Registry's continued growth, we sought to re-examine these metrics to assess the growth, change, and implications of Registry maturation in the context of the changing health care environment.

\section{Methods}

The Oregon Health \& Science University and the Oregon Public Health Department Institutional Review Boards deemed the study exempt because all data pertained to deceased persons.

The population included in the sample was Oregonians who died of natural causes in 2010 and 2011 (Cohort 1) and in 2015 and 2016 (Cohort 2). Death certificate data were provided from the Oregon Center for Health Statistics and included date of death, primary cause of death, age at death, location of death, decedent residence information, decedent date of birth, decedent race and ethnicity, and decedent educational attainment. POLST data were captured from the Oregon POLST Registry, matched deterministically with the death records, followed by manual review. Only the form completed closest to death for each registrant was included for those with multiple forms. POLST Registry data included final form orders for Section A: cardiopulmonary resuscitation (CPR) versus do not resuscitate (DNR) (attempt cardiopulmonary resuscitation vs. do not attempt resuscitation) and Section B: medical interventions (comfort measures only [CMO], limited treatment, or full treatment), as well as date of signature (Fig. 1).

\section{Analysis}

Univariate ( $t$-test and chi-square) and multivariate analyses were used to assess associations between demographic variables, having a POLST, POLST orders, and cohort. Variables from these unadjusted analyses showing significant differences were included in the logistic regression models. The models examined whether increases in the proportion of orders for life-sustaining treatment, particularly orders for "attempt resuscitation" and "full treatment," could be attributed to changes in demographics and diagnosis. Two primary models were developed; the dependent variable in the first model was having a POLST order of "attempt resuscitation" and the second model was having a final POLST order of "full treatment," each stratified by cohort. Analyses were conducted using IBM SPSS Statistics v. 25 (IBM Corp, Armonk, NY).

\section{Results}

The total number of deaths from natural causes increased in Oregon by 7498 (12.9\%) from 58,000 to 65,458 between time periods, while the number of forms increased by a much greater magnitude: $11,792(65.9 \%)$ from 17,902 to 29,694 (Table 1). Thus, the proportion of Oregon decedents with a registered POLST when they died increased by $46.6 \%$ from 30.9\% in Cohort 1 to $45.3 \%$ in Cohort 2 (Table 2). This $46.6 \%$ proportional increase in POLST use was not seen equally across all groups.

Using proportions to account for the increase in deaths that were not evenly distributed, there was little or no increase in POLST use for decedents aged 18 or younger or 19-44 years old, the age groups with the fewest numbers of decedents (2.9\% of all deaths). However, for decedents aged 45 and older, there was a steady rise in POLST use by age between the time periods: $18.6 \%$ for ages $45-64,31.7 \%$ for ages $65-$ $74,43.7 \%$ for ages $75-84,64.5 \%$ for ages $85-94$, and $83.3 \%$ for age 95 and older (Table 1).

POLST use among women increased by $52.5 \%$ (from $32.6 \%$ to $49.7 \%$ ), at a much higher rate than men, $41.0 \%$ (from $29 \%$ to $40.9 \%, p \leq 0.001$ ).

The majority of Oregon decedents are Caucasian and remain more likely than other racial/ethnic groups to use POLST. POLST use among Caucasians increased by $47.1 \%$ from Cohort 1 to Cohort 2. While they still do not use POLST as consistently as Caucasians, Asians and Pacific Islanders (74.8\% increase) and those reporting more than one race (65.2\% increase) began to close the gap. African Americans (38.1\% increase), Native Americans, and Native Alaskans (43.3\% increase), and particularly Hispanic/Latinos $(11.2 \%)$, saw the gap widen.

There remains an education gap in POLST use with the least educated using POLST $42.2 \%$ in Cohort 2 and the most educated using POLST $50.3 \%$ of the time. However, in Cohort 2, all education categories increased at rates greater than the highest category ( $47.6 \%$ to $49.7 \%$ compared to $43.3 \%$ ), so the gap closed slightly.

Malignant neoplasm remains the most common cause of death in Oregon and accounts for the largest number of POLST forms, but compared with Cohort 1 when malignant neoplasms were the cause of death most likely to have a POLST in the Registry, now Alzheimer's disease and dementia, chronic lower respiratory diseases, Parkinson's disease, and nephritis have a higher percentage. Looking at the amount of change from Cohort 1 to Cohort 2 by using the mean $46.6 \%$ increase in all causes of death for comparison, all causes of death $(56.0 \%$ to $86.5 \%)$ except malignant neoplasms (15.6\%) and liver disease $(25.4 \%)$ increased at a rate higher than the mean.

The time between final POLST completion and death increased substantially from Cohort 1 to Cohort 2-a fourfold increase from 5 to 21 weeks. Alzheimer's disease/dementia and Parkinson's disease had an approximately sixfold increase in the median time between last POLST completion (from 9 to 52 weeks, and from 6 to 37 weeks, respectively). Median time from final POLST to death did not change substantially for decedents with causes of death of cancer or liver disease.

Orders for "CPR vs. DNR" (Section A) and "medical interventions" (Section B) were significantly different among time periods (Table 3). While orders for "DNR" and "comfort measures only" were still the most prevalent and showed the greatest increases in absolute numbers, orders for "attempt CPR," "limited treatment," and "full treatment" increased at proportionally greater rates. 
HIPAA PERMITS DISCLOSURE TO HEALTH CARE PROFESSIONALS \& ELECTRONIC REGISTRY AS NECESSARY FOR TREATMENT Physician Orders for Life-Sustaining Treatment (POLST)

Follow these medical orders until orders change. Any section not completed implies full treatment for that section.

\begin{tabular}{|l|l|l|l|}
\hline Patient Last Name: & Patient First Name: & Patient Middle Name: & Last 4 SSN: \\
\hline Address: (street / city / state / zip): & Date of Birth: (mm/dd/yyy)
\end{tabular}

A CARDIOPULMONARY RESUSCITATION (CPR): Unresponsive, pulseless, \& not breathing.

Check $\square$ Attempt Resuscitation/CPR

One $\square$ Do Not Attempt Resuscitation/DNR

If patient is not in cardiopulmonary arrest, follow orders in $\mathbf{B}$ and $\mathbf{C}$.

B MEDICAL INTERVENTIONS: If patient has pulse and is breathing.

Check $\square$ Comfort Measures Only. Provide treatments to relieve pain and suffering through the use of any medication by any route, positioning, wound care and other measures. Use oxygen, suction and manual treatment of airway obstruction as needed for comfort. Patient prefers no transfer to hospital for life-sustaining treatments. Transfer if comfort needs cannot be met in current location. Treatment Plan: Provide treatments for comfort through symptom management.

$\square$ Limited Treatment. In addition to care described in Comfort Measures Only, use medical treatment, antibiotics, IV fluids and cardiac monitor as indicated. No intubation, advanced airway interventions, or mechanical ventilation. May consider less invasive airway support (e.g. CPAP, BiPAP). Transfer to hospital if indicated. Generally avoid the intensive care unit. Treatment Plan: Provide basic medical treatments.

$\square$ Full Treatment. In addition to care described in Comfort Measures Only and Limited Treatment, use intubation, advanced airway interventions, and mechanical ventilation as indicated. Transfer to hospital and/or intensive care unit if indicated.

Treatment Plan: All treatments including breathing machine.

Additional Orders:

C ARTIFICIALLY ADMINISTERED NUTRITION: Offer food by mouth if feasible.

$\square$ Long-term artificial nutrition by tube. Additional Orders (e.g., defining the length

$\square$ Defined trial period of artificial nutrition by tube. of a trial period):

$\square$ No artificial nutrition by tube.

\section{DOCUMENTATION OF DISCUSSION: (REQUIRED) See reverse side for add'l info.}

Must
Fill Out Patient (If patient lacks capacity, must check a box below)

$\square$ Health Care Representative (legally appointed by advance directive or court)

$\square$ Surrogate defined by facility policy or Surrogate for patient with developmental disabilities or significant mental health condition (Note: Special requirements for completion- see reverse side)

Representative/Surrogate Name:

Relationship:

E Patient or SurRogate Signature And OREgon POLST Registry Opt OUt

Signature: recommended

This form will be sent to the POLST Registry unless the patient wishes to opt out, if so check opt out box:

F ATtESTATION OF MD / DO / NP / PA (REQUIRED)

Must $\quad$ By signing below, I attest that these medical orders are, to the best of my knowledge, consistent with the patient's Print current medical condition and preferences.

Name, Print Signing MD / DO / NP / PA Name: required

Sign \&

Date

\begin{tabular}{|l|l|l|}
\hline MD / DO / NP / PA Signature: $\underline{\text { required }}$ & Date: $\underline{\text { required }}$ & Office Use Only
\end{tabular}

Signer Phone Number:

Signer License Number: (optional)

SEND FORM WITH PATIENT WHENEVER TRANSFERRED OR DISCHARGED

SUBMIT COPY OF BOTH SIDES OF FORM TO REGISTRY IF PATIENT DID NOT OPT OUT IN SECTION E

(c) CENTER FOR ETHICS IN HEALTH CARE, Oregon Health \& Science University.

FIG. 1. The 2014 Oregon POLST form. POLST, Physician Orders for Life-Sustaining Treatment.

Figure 2 shows a notable increase in POLST use in those older than 85 years. The median age of decedents with orders for "CPR" is substantially younger (age 84 vs. age 76). Proportional increases in "attempt CPR" orders were seen in all age groups from Cohort 1 to Cohort 2, but as Figure 2 illustrates, the proportions got smaller with each successive age category.

In the logistic regression models, increased age, female sex, Caucasian non-Hispanic race, higher education, and death due to cancer or dementia were all associated with 
Table 1. Demographics of Two Oregon Decedent Cohorts (2010-2011 and 2015-2016) with Proportion of Registered Physician Orders for Life-Sustaining Treatment Forms at Death and Proportional Change Between Cohorts

\begin{tabular}{|c|c|c|c|c|c|c|c|}
\hline & \multicolumn{3}{|c|}{ Cohort 1: 2010-2011 decedents } & \multicolumn{3}{|c|}{ Cohort 2: 2015-2016 decedents } & \multirow[b]{2}{*}{$\begin{array}{l}\text { Difference } \\
\text { Change in \% } \\
\text { between } \\
\text { cohorts }\end{array}$} \\
\hline & $\begin{array}{c}\text { Registered } \\
\text { POLST } \\
(\mathrm{n}=17,902) \\
\mathrm{n}\end{array}$ & $\begin{array}{c}\text { All natural } \\
\text { deaths } \\
(\mathrm{n}=58,000) \\
\mathrm{n}\end{array}$ & $\begin{array}{c}\text { Registered } \\
\text { POLST (30.9\% } \\
\text { of deaths) } \\
\%\end{array}$ & $\begin{array}{c}\text { Registered } \\
\text { POLST } \\
(\mathrm{n}=29,694) \\
\mathrm{n}\end{array}$ & $\begin{array}{c}\text { All natural } \\
\text { deaths } \\
(\mathrm{n}=65,498) \\
\mathrm{n}\end{array}$ & $\begin{array}{c}\text { Registered } \\
\text { POLST (45.3\% } \\
\text { of deaths) } \\
\%\end{array}$ & \\
\hline \multicolumn{8}{|l|}{ Age } \\
\hline$\leq 18$ & 32 & 536 & 6.0 & 33 & 492 & 6.7 & 11.7 \\
\hline $19-44$ & 212 & 1271 & 16.7 & 246 & 1450 & 17.0 & 1.8 \\
\hline $45-64$ & 2473 & 10,454 & 23.7 & 3185 & 11,328 & 28.1 & 18.6 \\
\hline $65-74$ & 2850 & 9717 & 29.3 & 5064 & 13,118 & 38.6 & 31.7 \\
\hline $75-84$ & 5068 & 14,953 & 33.9 & 7726 & 15,867 & 48.7 & 43.7 \\
\hline $85-94$ & 6083 & 17,416 & 34.9 & 10,676 & 18,587 & 57.4 & 64.5 \\
\hline$\geq 95$ & 1184 & 3653 & 32.4 & 2764 & 4656 & 59.4 & 83.3 \\
\hline \multicolumn{8}{|l|}{ Sex } \\
\hline Female & 9739 & 29,860 & 32.6 & 16,421 & 33,016 & 49.7 & 52.5 \\
\hline Male & 8163 & 28,140 & 29.0 & 13,273 & 32,481 & 40.9 & 41.0 \\
\hline \multicolumn{8}{|l|}{ Race } \\
\hline Caucasian & 17,275 & 55,358 & 31.2 & 28,354 & 61,805 & 45.9 & 47.1 \\
\hline $\begin{array}{l}\text { Asian, Native } \\
\text { Hawaiian, or } \\
\text { Pacific Islander }\end{array}$ & 194 & 828 & 23.4 & 484 & 1182 & 40.9 & 74.8 \\
\hline African American & 188 & 696 & 27.0 & 323 & 865 & 37.3 & 38.1 \\
\hline $\begin{array}{l}\text { American Indian } \\
\text { or Alaska Native }\end{array}$ & 105 & 442 & 23.8 & 196 & 574 & 34.1 & 43.3 \\
\hline Other & 78 & 399 & 19.5 & 182 & 653 & 27.9 & 43.1 \\
\hline$>1$ race reported & 62 & 277 & 22.4 & 155 & 419 & 37.0 & 65.2 \\
\hline \multicolumn{8}{|l|}{ Hispanic or Latino } \\
\hline Yes & 249 & 1113 & 22.4 & 400 & 1606 & 24.9 & 11.2 \\
\hline No & 17,653 & 56,887 & 31.0 & 29,294 & 63,892 & 45.8 & 47.7 \\
\hline \multicolumn{8}{|l|}{ Education } \\
\hline$<\mathrm{HS}$ & 3134 & 10,975 & 28.6 & 4403 & 10,434 & 42.2 & 47.6 \\
\hline HS/GED & 7286 & 23,622 & 30.8 & 11,828 & 26,001 & 45.5 & 47.7 \\
\hline Some college & 3243 & 10,198 & 31.8 & 5407 & 12,149 & 44.5 & 39.9 \\
\hline $\begin{array}{l}\text { Associate or } \\
\text { Bachelor's } \\
\text { degree }\end{array}$ & 2873 & 9047 & 31.8 & 5443 & 11,441 & 47.6 & 49.7 \\
\hline $\begin{array}{l}\text { Master's degree } \\
\text { or higher }\end{array}$ & 1150 & 3278 & 35.1 & 2255 & 4480 & 50.3 & 43.3 \\
\hline Unknown & 216 & 880 & 24.5 & 358 & 993 & 36.1 & 47.3 \\
\hline
\end{tabular}

GED, general educational development; HS, high school; POLST, Physician Orders for Life-Sustaining Treatment.

decreased likelihood of having orders to "attempt CPR" and/ or for "full treatment" on the final POLST form before death. Controlling for all these variables, decedents in Cohort 2 still had an increased likelihood of having more aggressive orders: "attempt CPR" (odds ratio $[\mathrm{OR}]=1.86,95 \%$ confidence interval $[\mathrm{CI}]=1.74-1.99)$ and "full treatment" $(\mathrm{OR}=1.89,95 \%$ $\mathrm{CI}=1.76-2.03)$ (Table 4).

\section{Discussion}

While deaths in Oregon increased $12.9 \%$ between the cohorts, the rate of increase in decedents with a POLST in the Registry increased nearly four times that rate $(46.6 \%)$. The change represents an absolute rise from $30.9 \%$ to $45.3 \%$ resulting in nearly half of those dying of natural causes having a POLST form in the Registry at the time of death in 20152016. It is not possible to distinguish from our data whether this increase is due to increased POLST use, or increased use of the POLST Registry, and probably both factors. For both POLST and Registry use, as with any innovation diffusion, there have been both early and late adopters and varying consistency among health systems, clinics, hospice programs, and skilled nursing facilities. There were substantially more senders in Cohort 2 (2015-2016), and form submissions per year continue to rise. ${ }^{21}$ Economic influences may also be contributing to higher POLST use in Cohort 2. In 2011, the Affordable Care Act expanded the Medicare annual wellness visit to include end-of-life care planning. In 2016, ACP conversations became a billable Medicare benefit. ${ }^{22,23}$ In addition, there is an overall reduction of transitions and expenditures near the end of life and a growing focus on coordinated care and ACP for patients with advanced illness. ${ }^{24,25}$

That said, there are several strong arguments for this increase being more related to registry use rather than the use of 
Table 2. Top 10 Natural Causes of Death with Proportion of Registered Physician Orders for Life-Sustaining Treatment Forms at Death and Proportional Change between Cohorts

\begin{tabular}{|c|c|c|c|c|c|c|c|c|c|}
\hline \multirow[b]{2}{*}{ Cause of death } & \multicolumn{4}{|c|}{ Cohort 1: 2010-2011 decedents } & \multicolumn{4}{|c|}{ Cohort 2: 2015-2016 decedents } & \multirow[b]{2}{*}{$\begin{array}{c}\text { Difference } \\
\% \text { increase } \\
\text { in registered } \\
\text { POLST }\end{array}$} \\
\hline & $\begin{array}{c}\text { All } \\
\text { natural } \\
\text { deaths } \\
\text { (n) }\end{array}$ & $\begin{array}{c}\text { Registered } \\
\text { POLST } \\
\text { (n) }\end{array}$ & $\begin{array}{c}\text { Registered } \\
\text { POLST } \\
(\%)\end{array}$ & $\begin{array}{l}\text { Median time } \\
\text { POLST } \\
\text { completed } \\
\text { before death } \\
\text { (rounded } \\
\text { to weeks) }\end{array}$ & $\begin{array}{c}\text { All } \\
\text { natural } \\
\text { deaths } \\
\text { (n) }\end{array}$ & $\begin{array}{c}\text { Registered } \\
\text { POLST } \\
\text { (n) }\end{array}$ & $\begin{array}{c}\text { Registered } \\
\text { POLST } \\
(\%)\end{array}$ & $\begin{array}{c}\text { Median time } \\
\text { POLST } \\
\text { completed } \\
\text { before death } \\
\text { (rounded } \\
\text { to weeks) }\end{array}$ & \\
\hline $\begin{array}{l}\text { Malignant } \\
\text { neoplasms }\end{array}$ & 14,980 & 6146 & 41.0 & 4 & 16,198 & 7685 & 47.4 & 7 & 15.6 \\
\hline Heart diseases & 11,799 & 2967 & 25.1 & 7 & 13,656 & 5689 & 41.7 & 30 & 66.1 \\
\hline $\begin{array}{l}\text { Alzheimer's } \\
\text { disease and } \\
\text { dementia }\end{array}$ & 6118 & 2122 & 34.7 & 9 & 6850 & 4246 & 62.0 & 52 & 78.7 \\
\hline $\begin{array}{l}\text { Chronic lower } \\
\text { respiratory } \\
\text { diseases }\end{array}$ & 3918 & 1211 & 30.9 & 7 & 4181 & 2015 & 48.2 & 28 & 56.0 \\
\hline $\begin{array}{l}\text { Cerebrovascular } \\
\text { diseases }\end{array}$ & 3603 & 996 & 27.6 & 5 & 3203 & 1387 & 43.3 & 35 & 56.9 \\
\hline Diabetes mellitus & 2126 & 526 & 24.7 & 6 & 2381 & 949 & 39.9 & 32 & 61.5 \\
\hline Liver disease & 1024 & 246 & 24.0 & 3 & 1271 & 383 & 30.1 & 4 & 25.4 \\
\hline $\begin{array}{l}\text { Influenza and } \\
\text { pneumonia }\end{array}$ & 779 & 162 & 20.8 & 6 & 892 & 346 & 38.8 & 49 & 86.5 \\
\hline $\begin{array}{l}\text { Parkinson's } \\
\text { disease }\end{array}$ & 695 & 248 & 35.7 & 6 & 871 & 573 & 65.8 & 37 & 84.3 \\
\hline Nephritis & 699 & 221 & 31.6 & 5 & 793 & 421 & 53.1 & 26 & 68.0 \\
\hline All others & 12,259 & 3057 & 24.9 & 6 & 15,202 & 6000 & 39.5 & 31 & 58.6 \\
\hline All causes & 58,000 & 17,902 & 30.9 & 5 & 65,498 & 29,694 & 45.3 & 21 & 46.6 \\
\hline
\end{tabular}

POLST alone. First, POLST has been used in Oregon since 1993 and use has been widespread for more than 20 years. $^{2}$ Second, in Cohort 1, the Registry was brand new and while new POLST forms were required to be submitted, there was not a clear mandate for health systems to search through medical records to identify and submit older pre-existing POLST forms. ${ }^{26}$ Third, the substantial increases in time between last POLST form and death from Cohort 1 to Cohort 2 point to the Registry being brand new in Cohort 1 and relatively more "mature" in Cohort 2. While most of the decedents in Cohort 1 had their POLST forms completed during Cohort 1, decedents in Cohort 2 could have had their forms completed any time from 2010 to 2016 . Maturity is relative because while Oregon's POLST Registry is the oldest and most established of its kind, it continues to evolve. ${ }^{27}$

Older adults remain the vast majority of POLST users. Although the median age of POLST users increased by only 1 year from age 82 in Cohort 1 to age 83 in Cohort 2, the oldest old had the greatest proportional increases in POLST use: $64.5 \%$ for ages $85-94$ and $83.3 \%$ for ages $95+$. With this shift toward the oldest old, POLST use increased at a faster rate among women than among men. We also see the greatest increase in POLST use among the causes of death diagnoses most commonly associated with the frailty trajectory-

Table 3. Registered Physician Orders for Life-Sustaining Treatment Form Orders with Absolute DIFFERENCE BETWEEN COHORTS

\begin{tabular}{|c|c|c|c|c|c|}
\hline & \multicolumn{2}{|c|}{$\begin{array}{c}\text { Cohort 1: } \\
\text { 2010-2011 decedents }\end{array}$} & \multicolumn{2}{|c|}{$\begin{array}{c}\text { Cohort 2: } \\
\text { 2015-2016 decedents }\end{array}$} & \multirow{2}{*}{$\begin{array}{c}\text { Cohort difference } \\
\% \text { change in } \\
\text { order selection }\end{array}$} \\
\hline & $\mathrm{n}$ & $\%$ & $\mathrm{n}$ & $\%$ & \\
\hline \multicolumn{6}{|l|}{ Section A orders* } \\
\hline CPR & 1334 & 7.5 & 3810 & 12.8 & 185.6 \\
\hline DNR & 16,568 & 92.5 & 25,875 & 87.1 & 56.2 \\
\hline \multicolumn{6}{|l|}{ Section B orders* } \\
\hline Full treatment & 1153 & 6.4 & 3359 & 11.3 & 191.3 \\
\hline Limited treatment & 4787 & 26.7 & 10,839 & 36.5 & 126.4 \\
\hline Comfort measures only & 11,836 & 66.1 & 15,316 & 51.6 & 29.4 \\
\hline Not filled out & 126 & 0.7 & 180 & 0.6 & 42.9 \\
\hline
\end{tabular}

${ }^{\mathrm{a}}$ Calculated as absolute number increase between cohorts with Cohort 1 as denominator. $* p<0.001$

CPR, cardiopulmonary resuscitation; DNR, do not resuscitate. 


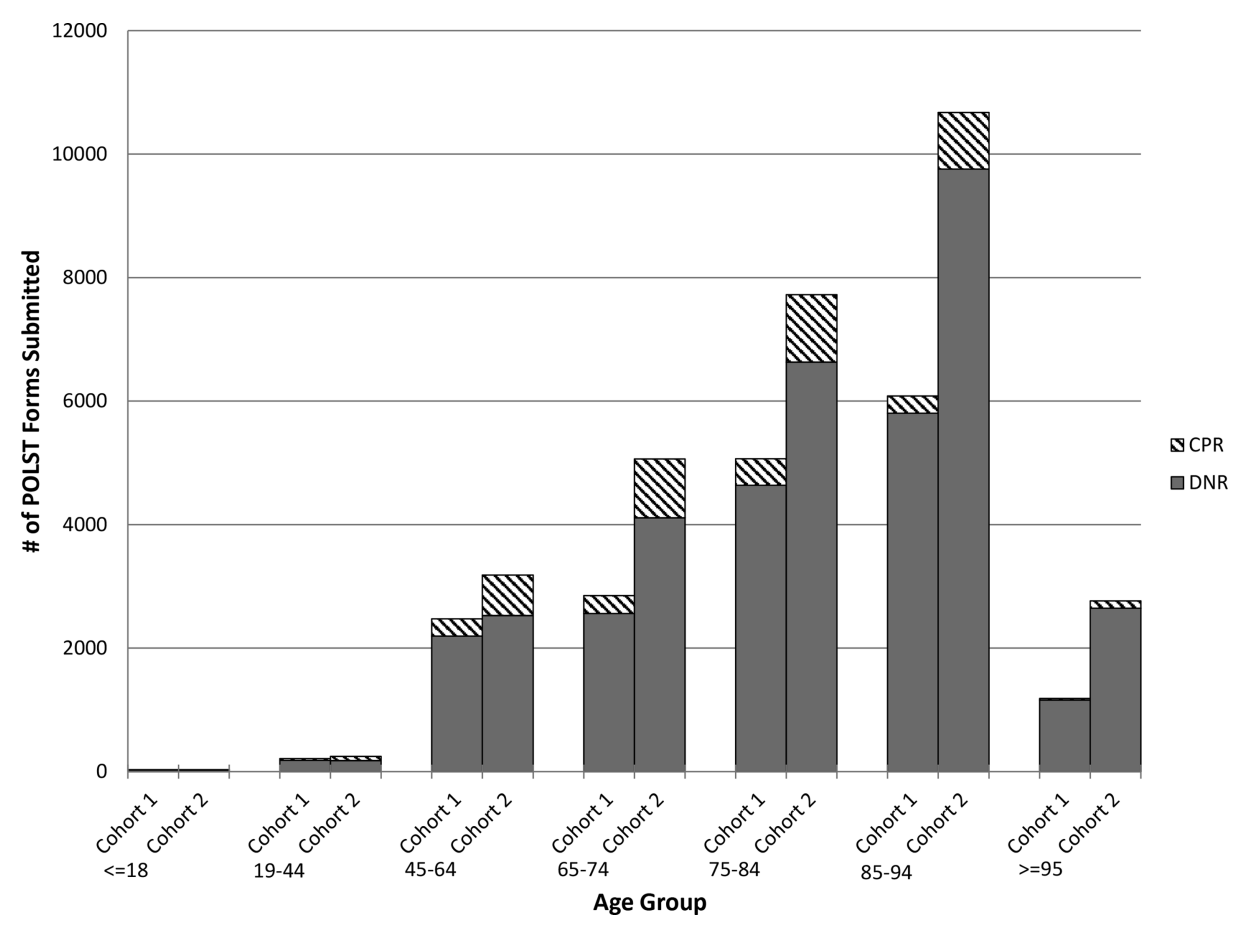

FIG. 2. Number of registered POLST form orders for DNR and CPR by cohort and age group. CPR, cardiopulmonary resuscitation; DNR, do not resuscitate.

Alzheimer's disease and Parkinson's disease. Two-thirds of persons with these diagnoses now have a POLST form in the Registry at the time of death.

It is important to note that the median period of time between final POLST form completion and death for persons with Alzheimer's disease and other forms of dementia is 52 weeks. Many patients with Alzheimer's disease and other frailty diagnoses complete POLST forms substantially before the time of their death. This has policy implications because currently, POLST educational materials suggest using the surprise question ("Would you be surprised if the patient died in the next year?") to determine who should have the opportunity to complete a form. The surprise question may be helpful for patients with other illnesses such as cancer, but it may be an especially poor fit for those with a much slower decline with advanced age, cognitive impairment, and frail-

Table 4. Logistic Regression Results with Outcome of Cardiopulmonary Resuscitation Orders (MOdel 1) and Full Treatment Orders (Model 2)

\begin{tabular}{lcc}
\hline & $\begin{array}{c}\text { Model 1: Outcome: } \\
\text { CPR orders on } \\
\text { final POLST form } \\
\text { odds ratio (95\% CI) }\end{array}$ & $\begin{array}{c}\text { Model 2: Outcome: } \\
\text { full treatment orders } \\
\text { on final POLST form } \\
\text { odds ratio (95\% CI) }\end{array}$ \\
\hline Cohort & $1.864(1.744-1.993)$ & $1.889(1.759-2.028)$ \\
Age & $0.966(0.964-0.968)$ & $0.965(0.962-0.967)$ \\
Female & $0.843(0.794-0.895)$ & $0.832(0.781-0.886)$ \\
>HS/GED & $0.953(0.898-1.012)$ & $0.941(0.883-1.003)$ \\
White & $0.693(0.611-0.786)$ & $0.621(0.547-0.706)$ \\
Cancer & $0.418(0.388-0.451)$ & $0.399(0.368-0.432)$ \\
Alzheimer's & $0.464(0.413-0.522)$ & $0.408(0.358-0.465)$ \\
$\quad$ or dementia & &
\end{tabular}

CI, confidence interval. ty. ${ }^{10,28-32}$ In a recent study about ACP in those with documentation of frailty, only $10 \%$ died in a $12-$ month period and yet many wanted to engage in ACP and have a DNR order. ${ }^{33}$

Compared with Cohort 1, Cohort 2 contains disproportionate increases in all "higher" levels of life-sustaining treatment orders, a finding that was confirmed for "attempt CPR" and "full treatment" orders in the logistic regression models. Figure 2 shows the proportions of "attempt CPR" versus "DNR" by age category to demonstrate two important points - first, while the proportion of patients opting to "attempt CPR" increased in all age groups, the inverse relationship between "attempt CPR" and increasing age remained in effect with a lower percentage of "attempt CPR" orders with each increasing age category above 45 years. Second, while the proportion of "attempt CPR" and "full treatment" orders increased dramatically, the absolute numbers of new "DNR" and "CMO" orders were substantially greater.

It is worth considering what this shift toward more aggressive treatment represents. It may be an artifact caused by hospice programs that routinely use POLST, but do not routinely submit their forms to the Registry, telling patients to call hospice rather than Emergency Medical Services (EMS). Thus, the Registry would not reflect the most current POLST form for those decedents. It may also be that POLST use is spreading to patients who previously would not have completed POLST and who also have preferences for more aggressive treatment. If these orders for aggressive treatment accurately reflect the preferences of these decedents, that would not be a cause for concern, however, there is another possibility related to the increases in time between POLST completion and death. Previous studies of changes in POLST forms over time show that most patients who complete more than one form move toward lower levels of treatment as they approach death. $6,15,17-19$ Therefore, it seems plausible that the increasing proportions of patients with orders for higher levels 
of treatment could be related to the increasing time between POLST completion and death. This begs the following question: how often do POLST orders for " attempt CPR" and "full treatment" completed months before death still reflect patient preferences at the time of death?

While the secular trend toward more and earlier ACP and serious illness communication is extremely positive, ${ }^{34-40}$ documenting patient preferences to "attempt CPR" and "full treatment" years before death may have unintended consequences if the orders are not revisited when health status changes. $^{41}$

This study has a number of limitations. Despite being the most widely used POLST Registry in the United States, ${ }^{27}$ the Registry still underestimates POLST use in Oregon. Some health care organizations fail to submit forms consistently, and some patients opt out of having their forms registered. A large number of submitted POLST forms lack legible critical information (such as patient identifiers, signatures, or dates) and cannot be entered into the Registry. ${ }^{21}$ We used death certificate data to classify cause of death. For some diseases, such as endstage dementia, substantial underreporting occurs. In one prospective study of nursing home residents with end-stage dementia, pneumonia was reported more frequently as the cause of death than dementia. ${ }^{42}$

Finally, the study uses data from only one state, Oregon, and its unique POLST program. ${ }^{43}$ End-of-life practices vary by region and so our data, particularly life-sustaining treatment orders, may not reflect other states, especially those with greater racial and ethnic diversity. ${ }^{4,45}$

\section{Conclusion}

Based on these findings, we recommend a different approach to the timing of POLST completion for those with declining cognitive function and frailty, acknowledging that significantly more than a year before death they may wish to set limits on some medical treatments. We also assume that, as long as the presumption for those without POLST remains firmly to "attempt CPR" and provide "full treatment," there is a greater potential for harm in documenting these preferences in patients who are not terminally ill and may have years left to live. As an alternative to the question "Would you be surprised if this person were to die in the next year?" we propose testing the following criteria for POLST in frail elders. (1) Patient has had serious illness conversations, including values, priorities, and preferences for life-sustaining treatment. (2) They are beginning to need assistance because of physical or cognitive decline. (3) Patient expresses an interest in setting some limits on life-sustaining treatment.

\section{Acknowledgment}

This study was supported by a grant from The Denison Family Fund of the Oregon Community Foundation.

\section{Author Disclosure Statement}

Ms. D.M.Z. reports grant support from The Denison Family Fund of the Oregon Community Foundation. Ms. D.M.Z also receives salary support from the Oregon POLST Registry, which operates at OHSU under contract with the Oregon Health Authority. Ms. V.M.J. receives salary support from the OHSU Center for Ethics in Health Care. The OHSU Center for
Ethics in Health Care administers the Oregon POLST Program. Dr. E.K.F. reports grants from The Gordon and Betty Moore Foundation and The John A. Hartford Foundation. Dr. S.W.T. reports grants from The Kinsman Foundation and The Denison Family Fund of the Oregon Community Foundation and receives salary support from the OHSU Center for Ethics in Health Care. The OHSU Center for Ethics is supported by private philanthropy and does not accept gifts from health care industry sources.

\section{References}

1. Institute of Medicine (IOM): Key findings and recommendations: Dying in America: Improving quality and honoring individual preferences near the end of life, 2014. www.nationalacademies.org/hmd/ /media/Files/Report $\% 20$ Files/2014/EOL/Key\%20Findings\%20and\%20Recommend ations.pdf (last accessed August 10, 2018).

2. Oregon POLST Program website: Oregon POLST History. www.oregonpolst.org/history (Last accessed August 10, 2018).

3. Dunn PM, Schmidt TA, Carley MM, et al.: A method to communicate patient preferences about medically indicated life-sustaining treatment in the out-of-hospital setting. J Am Geriatr Soc 1996;44:785-791.

4. Tolle SW, Tilden VP, Nelson CA, et al.: A prospective study of the efficacy of the physician order form for life-sustaining treatment. J Am Geriatr Soc 1998;46: 1097-1102.

5. Jennings LA, Zingmond D, Louie R, et al.: Use of the physician orders for life-sustaining treatment among California nursing home residents. J Gen Intern Med 2016;31: 1119-1126.

6. Schmidt TA, Zive D, Fromme EK, et al.: Physician Orders for Life-Sustaining Treatment (POLST): Lessons learned from analysis of Oregon POLST registry. Resuscitation 2014;85:480-485.

7. Schmidt TA, Hickman SE, Tolle SW, et al.: The Physician Orders for Life-Sustaining Treatment program: Oregon emergency medical technicians' practical experiences and attitudes. J Am Geriatr Soc 2004;52:1430-1434.

8. Richardson DK, Fromme E, Zive D, et al.: Concordance of out-of-hospital and emergency department cardiac arrest resuscitation with documented end-of-life choices in Oregon. Ann Emerg Med 2014;63:375-383.

9. Schmidt TA, Olszewski EA, Zive D, et al.: The Oregon Physician Orders for Life-Sustaining Treatment registry: A preliminary study of emergency medical services utilization. J Emerg Med 2013;44:796-805.

10. Hickman SE, Nelson CA, Perrin NA, et al.: A comparison of methods to communicate treatment preferences in nursing facilities: Traditional practice versus the physician orders for life-sustaining treatment program. J Am Geriatr Soc 2010;58:1241-1248.

11. Hickman SE, Nelson CA, Moss AH, et al.: The consistency between treatments provided to nursing facility residents and orders on the physician orders for life-sustaining treatment form. J Am Geriatr Soc 2011;59:2091-2099.

12. Hickman SE, Nelson CA, Smith-Howell E, et al.: Use of the physician orders for life-sustaining treatment program for patients being discharged from the hospital to the nursing facility. J Palliat Med 2014;17:43-49.

13. Hammes BJ, Rooney BL, Gundrum MS, et al.: The POLST program: A retrospective review of the demographics of 
use and outcomes in one community where advance directives are prevalent. J Palliat Med 2012;15:77-85.

14. Caprio AJ, Rollins VP, Roberts E: Health care professionals' perceptions and use of the Medical Orders for Scope of Treatment (MOST) form in North Carolina nursing homes. J Am Med Dir Assoc 2012;13:162-168.

15. Fromme EK, Zive D, Schmidt T, et al.: Association between physician orders for life-sustaining treatment for scope of treatment and in-hospital death in Oregon. J Am Geriatr Soc 2014;62:1246-1251.

16. Fromme EK, Zive D, Schmidt TA, et al.: POLST registry do-not-resuscitate orders and other patient treatment preferences. JAMA 2012;307:34-35.

17. Zive DM, Fromme EK, Schmidt TA, et al.: Timing of POLST form completion by cause of death. J Pain Symptom Manage 2015;50:650-658.

18. Pedraza SL, Culp S, Falkenstine EC, et al.: POST forms more than advance directives associated with out-of-hospital death: Insights from a state registry. J Pain Symptom Manage 2016;51:240-246.

19. Hopping-Winn J, Mullin J, March L, et al.: The progression of end-of-life wishes and concordance with end-of-life care. J Palliat Med 2018;21:541-545.

20. Oregon POLST Registry Act: House Bill 2009. Oregon Administrative Rules ch. 595, Sec. 1184, 2009. https://olis .leg.state.or.us/liz/2009R1/Downloads/MeasureDocument/ HB2009/Enrolled (last accessed August 10, 2018).

21. Oregon POLST Registry website: 2016 Oregon POLST Registry Annual Report. www.orpolstregistry.org/wp-content/ uploads/2012/09/2016-Oregon-POLST-Registry-AnnualReport_FINAL_For_Distribution-1.pdf (Last accessed August 10, 2018).

22. Centers for Medicare \& Medicaid Services website: Frequently Asked Questions About Billing the Physician Fee Schedule for Advance Care Planning Services. www.cms.gov/ Medicare/Medicare-Fee-for-Service-Payment/PhysicianFee Sched/Downloads/FAQ-Advance-Care-Planning.pdf (Last accessed August 10, 2018).

23. Kaiser Family Foundation website: 10 FAQs: Medicare's Role in End-of-Life Care. www.kff.org/medicare/factsheet/10-faqs-medicares-role-in-end-of-life-care (Last accessed August 10, 2018).

24. Weeks WB, Kirkland KB, Freeh C, et al.: Proportion of decedents' expenditures among recent reductions in medicare expenditures. JAMA Intern Med 2018;178:717-719.

25. Teno JM, Gonzalo P, Trivedi AM, et al.: Site of death, place of care, and health care transitions among US medicare beneficiaries, 2000-2015. JAMA 2017;320:264-271.

26. Oregon Health Authority website: About the Oregon Physician Orders for Life-Sustaining Treatment (POLST) Program. www.oregon.gov/oha/PH/ProviderPartnerResources/EMS TraumaSystems/PhysicianOrdersforLifeSustainingTreatment/ Pages/index.aspx (Last accessed August 10, 2018).

27. The Office of the National Coordinator for Health Information Technology website: Electronic End-of-Life and Physician Orders for Life-Sustaining Treatment (POLST) Documentation Access through Health Information Exchange (HIE). www.healthit.gov/sites/default/files/topiclanding/201807/POLSTRegistryKnowledge.pdf (Last accessed August 10, 2018).

28. Lunney JR, Lynn J, Foley DJ, et al.: Patterns of functional decline at the end of life. JAMA 2003;289:2387-2392.
29. Lunney JR, Lynn J: Trajectories of disability in the last year of life. N Engl Med 2010;363:294.

30. Billings JA, Bernacki R: Strategic targeting of advance care planning interventions: The Goldilocks phenomenon. JAMA Intern Med 2014;174:620-624.

31. Ballentine JM: The Five Trajectories: Supporting Patients During Serious Illness. The California State University Institute for Palliative Care. www.csupalliativecare.org/ programs/clinicians-essentials/five-trajectories-ebook, 2018. (Last accessed August 10, 2018).

32. Downar J, Goldman R, Pinto R, et al.: The "surprise question" for predicting death in seriously ill patients: A systematic review and meta-analysis. CMAJ 2017;189: E484-E493.

33. Overbeek A, Korfage IJ, Jabbarian LJ, et al.: Advance care planning in frail older adults: A cluster randomized controlled trial. J Am Geriatr Soc 2018;66:1089-1095.

34. The Conversation Project website: The Conversation Project Starter Kits. www.theconversationproject.org (Last accessed August 10, 2018).

35. PREPARE for your care website: The PREPARE Pamphlet. www.prepareforyourcare.org/pamphlet (Last accessed August 10, 2018).

36. ACP Decisions website: ACP Free Patient Content. www .acpdecisions.org/patients (Last accessed August 10, 2018).

37. Death Cafe website: What is Death Cafe? www.death cafe.com/what (Last accessed August 10, 2018).

38. Respecting Choices ${ }^{\circledR}$ website: Respecting Choices ${ }^{\circledR}$ Overview of Programs and Services. www.respectingchoices.org/ overview-of-programs-and-services (Last accessed August 10, 2018).

39. Ariadne Labs website: The Serious Illness Care Program. www.ariadnelabs.org/areas-of-work/serious-illness-care (Last accessed August 10, 2018).

40. VitalTalk website: VitalTalk Clinicians. www.vitaltalk.org/ clinicians (Last accessed August 10, 2018).

41. Tolle SW, Teno JM: Counting POLST Form Completion Can Hinder Quality. 2018. www.healthaffairs.org/do/ 10.1377/hblog20180709.244065/full (Last accessed August 10, 2018).

42. Wachterman M, Kiely DK, Mitchell SL: Reporting dementia on the death certificates of nursing home residents dying with end-stage dementia. JAMA 2008; 300:26082610.

43. Tolle SW, Teno JM: Lessons from Oregon in embracing complexity in end-of-life care. N Engl J Med 2017;376: 1078-1082.

44. Barnato AE, Herndon MB, Anthony DL, et al.: Are regional variations in end-of-life care intensity explained by patient preferences? A Study of the US medicare population. Med Care 2007;453:86-393.

45. Barnato AE: Challenges in understanding and respecting patients' preferences. Health Aff 2017;36:1252-1257.

Address correspondence to: Valerie M. Jimenez, BS Center for Ethics in Health Care Oregon Health \& Science University 3181 SW Sam Jackson Park Road, UHN-86 Portland, OR 97239

E-mail: jimenezv@ohsu.edu 